\title{
Reliable determination of new lipid peroxidation compounds as potential early Alzheimer Disease biomarkers
}

\author{
Ana García-Blanco ${ }^{a, b}$, Carmen Peña-Bautista ${ }^{a}$, Camille Oger ${ }^{c}$, Claire Vigor ${ }^{c}$, Jean-Marie Galano ${ }^{c}$, \\ Thierry Durand ${ }^{\mathrm{c}}$, Nuria Martín-Ibáñez ${ }^{\mathrm{d}}$, Miguel Baquero ${ }^{\mathrm{d}}$, Máximo Vento ${ }^{\mathrm{a}}$, \\ Consuelo Cháfer-Pericás ${ }^{\mathrm{a}, *}$ \\ ${ }^{a}$ Neonatal Research Unit, Health Research Institute La Fe, Valencia, Spain \\ ${ }^{\mathrm{b}}$ University of Valencia, Valencia, Spain \\ ${ }^{\mathrm{c}}$ Institut des Biomolécules Max Mousseron (IBMM), UMR 5247, CNRS, University of Montpellier, ENSCM, Montpellier, France \\ ${ }^{\mathrm{d}}$ Neurology Unit, University and Polytechnic Hospital La Fe, Valencia, Spain
}

\section{A R T I C L E I N F O}

\section{Keywords:}

Lipid peroxidation

Neurological damage

Urine

Mass spectrometry

Biomarker

Isoprostane

Isofuran

\begin{abstract}
A B S T R A C T
Lipid peroxidation plays an important role in Alzheimer Disease, so corresponding metabolites found in urine samples could be potential biomarkers. The aim of this work is to develop a reliable ultra-performance liquid chromatography-tandem mass spectrometry analytical method to determine a new set of lipid peroxidation compounds in urine samples.

Excellent sensitivity was achieved with limits of detection between 0.08 and $17 \mathrm{nmol} \mathrm{L}^{-1}$, which renders this method suitable to monitor analytes concentrations in real samples. The method's precision was satisfactory with coefficients of variation around 5-17\% (intra-day) and 8-19\% (inter-day). The accuracy of the method was assessed by analysis of spiked urine samples obtaining recoveries between $70 \%$ and $120 \%$ for most of the analytes. The utility of the described method was tested by analyzing urine samples from patients early diagnosed with mild cognitive impairment or mild dementia Alzheimer Disease following the clinical standard criteria. As preliminary results, some analytes $\left(17(R S)-10\right.$-epi-SC- $\Delta^{15}-11$-dihomo-IsoF, PGE 2 ) and total parameters (Neuroprostanes, Isoprostanes, Isofurans) show differences between the control and the clinical groups. So, these analytes could be potential early Alzheimer Disease biomarkers assessing the patients' pro-oxidant condition.
\end{abstract}

\section{Introduction}

Alzheimer Disease (AD) is characterized by changes in brain, Mild Cognitive Impairment (MCI), and pathological levels of biomarkers ( $\beta$ amyloid, total tau, and phosphorylated-tau proteins) in cerebrospinal fluid (CSF) samples $[1,2]$. However, CSF samples are obtained by invasive techniques [3], so the reliable determination of potential AD biomarkers in non-invasive samples is required.

Oxidative stress plays a major role in the pathogenesis of AD [4-7]. Of note, lipid peroxidation is the most promising oxidative stress process, since brain has a high and specific lipid composition [8-10]. The peroxidation by-products from brain lipids include $\mathrm{F}_{2}$-isoprostanes and isofurans $\left(\mathrm{F}_{2}\right.$-IsoP, IsoF), $\mathrm{F}_{4}$-neuroprostanes and neurofurans $\left(\mathrm{F}_{4^{-}}\right.$ NeuroP and NeuroF), and $\mathrm{F}_{2}$-dihomo-isoprostanes and dihomo-isofurans (dihomo-IsoP and dihomo-IsoF) [11]. Preliminary research shows high levels of IsoPs and NeuroPs in AD brain [12], CSF, urine, and plasma samples [13-16]. Urine is the most non-invasively achievable biofluid that contains lipid peroxidation metabolites [17]. However, its sample treatment shows some difficulties (low concentrations, interferences, glucuronic acid conjugation), so additional sample treatment steps are required $[18,19]$.

The developed analytical methods to determine lipid peroxidation biomarkers in urine samples are mainly based on gas chromatography (GC) coupled to mass spectrometry (MS) [20], but these methods require a tedious and time-consuming derivatization, and they show low capacity to identify different isomers [21]. Also, immunoassays have been employed [22], with the drawbacks of poor selectivity, and results not comparable to chromatographic results [23].

In contrast, the liquid chromatography coupled to mass spectrometry (LC-MS/MS) provides high sensitivity and selectivity [24]. However, few LC methods have been applied to human urine samples [25], and most of them show high retention times, and long chromatograms [26-28].

\footnotetext{
* Correspondence to: Health Research Institute La Fe, Avda de Fernando Abril Martorell, 106, 46026 Valencia, Spain

E-mail address: m.consuelo.chafer@uv.es (C. Cháfer-Pericás).
} 
The aim of this work was to develop a reliable analytical method to determine lipid peroxidation biomarkers in urine samples. Then, this method was applied to samples from AD patients. For this, we used simple sample treatment and ultra-performance liquid chromatography-tandem mass spectrometry (UPLC-MS/MS). To our knowledge, this is the first LC validated method to determine simultaneously 17 lipid peroxidation biomarkers in urine samples, and it could be applied in further clinical studies.

\section{Materials and methods}

\subsection{Participants, urine collection, and storage}

The Ethics Committee (CEIC) at the Health Research Institute La Fe (Valencia) approved the study protocol and informed consent was obtained from all the participants. Patients aged between 50 and 75 years old were recruited from the Neurology Unit in the University and Polytechnic Hospital La Fe, Valencia (Spain). Participants were classified into 3 groups (control, MCI-AD, and mild dementia AD) based on psychological testing, structural neuroimaging (NMR-TAC), and CSF biomarkers as shown in Electronic Supplementary material Table S1 $[29,30]$. The characteristics of participants in this study are summarized in Electronic Supplementary material Table S2. Questionnaires addressing the neuropsychological assessment (Repeatable Battery for Assessment of Neuropsychological Status-RBANS-MR) [31], the functionality (Functionality Assessment Questionnaire - FAQ) [32] and the clinical dementia (Clinical Dementia Rating-CDR) [33] were conducted to all participants, and urine samples were collected in sterile pots with screw caps. Thereafter, urine samples were aliquoted in tubes and stored at $-80^{\circ} \mathrm{C}$ until analysis.

\subsection{Reagents}

Isoprostanes' standards of $15(R)-15-\mathrm{F}_{2 \mathrm{t}}$-IsoP, 2,3-dinor-15-epi-15$\mathrm{F}_{2 \mathrm{t}^{-}}$IsoP, 5- $\mathrm{F}_{2 \mathrm{t}}$-IsoP, 15-keto-15- $\mathrm{E}_{2 \mathrm{t}^{-}}$-IsoP, 15-keto-15- $\mathrm{F}_{2 \mathrm{t}^{-}}$-IsoP, 15- $\mathrm{E}_{2 \mathrm{t}^{-}}$ IsoP, 15- $\mathrm{F}_{2 \mathrm{t}}$-IsoP, the prostaglandins $\mathrm{PGE}_{2}$ and $\mathrm{PGF}_{2 \alpha}$, as well as the deuterated internal standard (IS) $\mathrm{PGF}_{2 \alpha}-\mathrm{d}_{4}$ were purchased from Cayman Chemical Company (Ann Arbor, Michigan, USA). The standards of $7(R S)$-ST- $\Delta^{8}-11$-dihomo-IsoF, 10-epi-10- $\mathrm{F}_{4 \mathrm{t}}$-NeuroP, $\mathrm{d}_{4}-10$ -

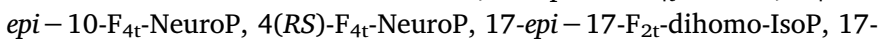
$\mathrm{F}_{2 \mathrm{t}}$-dihomo-IsoP, $17(R S)-10$-epi-SC- $\Delta^{15}-11$-dihomo-IsoF, Ent$7(R S)-7-\mathrm{F}_{2 \mathrm{t}}$-dihomo-IsoP, and $14(R S)-14-\mathrm{F}_{4 \mathrm{t}}$-NeuroP were synthetized by Durand's team at the Institute des Biomolécules Max Mousseron (IBMM) (Montpellier, France) (Fig. S1 in Electronic Supplementary material) [34]. Methanol (LC-MS grade) and n-heptane (analytical grade) were obtained from J.T. Baker (Avantor Performance Materials B.V., The Netherlands). Chlorhydric acid and acetic acid glacial (99.5\%) were purchased from Panreac (Castellar del Vallés, Barcelona, Spain). Ammonium acetate, sodium acetate, sodium hydroxide, and $\beta$-glucuronidase (type $\mathrm{H} 2$, from Helix pomatia) were purchased from Sigma-Aldrich (St. Louis, MO, USA). Creatinine assay (MicroVue creatinine EIA) from Quidel Corporation (San Diego, CA, USA).

\subsection{Solutions}

Individual stock solutions of 15-keto-15- $\mathrm{E}_{2 \mathrm{t}}-\mathrm{IsoP}, 15-\mathrm{keto}^{-15}-\mathrm{F}_{2 \mathrm{t}}{ }^{-}$ IsoP, $\mathrm{PGE}_{2}, 15-\mathrm{E}_{2 \mathrm{t}}$-IsoP, $15-\mathrm{F}_{2 \mathrm{t}}-\mathrm{IsoP}_{1} \mathrm{PGF}_{2 \alpha}, \mathrm{PGF}_{2 \alpha}-\mathrm{d}_{4}, 7(R S)-\mathrm{ST}-\Delta^{8}-11-$ dihomo-IsoF, 5- $\mathrm{F}_{2 \mathrm{t}}$-IsoP, 10-epi-10- $\mathrm{F}_{4 \mathrm{t}^{-}}$NeuroP, $\mathrm{d}_{4}-10-e p i-10-\mathrm{F}_{4 \mathrm{t}^{-}}$ NeuroP, 4(RS)- $\mathrm{F}_{4 \mathrm{t}}$-NeuroP, 17-epi-17- $\mathrm{F}_{2 \mathrm{t}}$-dihomo-IsoP, 17- $\mathrm{F}_{2 \mathrm{t}}$-dihomoIsoP, $17(R S)-10$-epi-SC- $\Delta^{15}-11$-dihomo-IsoF, Ent-7 $(R S)-7-\mathrm{F}_{2 \mathrm{t}}$-dihomo-IsoP, and $14(R S)-14-\mathrm{F}_{4 \mathrm{t}}$-NeuroP standards at a concentration of $1 \mathrm{mmol} \mathrm{L}^{-1}$ were prepared in $\mathrm{H}_{2} \mathrm{O}\left(0.01 \% \mathrm{v} / \mathrm{v} \quad \mathrm{CH}_{3} \mathrm{COOH}, \mathrm{pH}\right.$ 3): $\mathrm{CH}_{3} \mathrm{OH}(85: 15 \mathrm{v} / \mathrm{v})$ and kept at $-20{ }^{\circ} \mathrm{C}$. $15(R)-15-\mathrm{F}_{2 \mathrm{t}}$-IsoP and 2,3dinor-15-epi-15- $\mathrm{F}_{2 \mathrm{t}}$-IsoP standards were dissolved in methyl acetate or ethanol, at a concentration of 2800 or $300 \mu \mathrm{mol} \mathrm{L}^{-1}$, respectively, and used as stock solutions. A $2.5 \mu \mathrm{mol} \mathrm{L}^{-1}$ working solution of the set of analytes was prepared in $\mathrm{H}_{2} \mathrm{O}\left(0.01 \% \mathrm{v} / \mathrm{v} \mathrm{CH}_{3} \mathrm{COOH}, \mathrm{pH} 3\right): \mathrm{CH}_{3} \mathrm{OH}$ $(85: 15 \mathrm{v} / \mathrm{v})$ by mixing appropriate volumes of the above mentioned individual solutions, and kept at $-20^{\circ} \mathrm{C}$. The calibration curves were prepared daily by serial dilution in $\mathrm{H}_{2} \mathrm{O}(\mathrm{pH} 3): \mathrm{CH}_{3} \mathrm{OH}(85: 15 \mathrm{v} / \mathrm{v})$ at concentrations ranging from $300 \mathrm{nmol} \mathrm{L}^{-1}$ to $0.004 \mathrm{nmol} \mathrm{L}^{-1}$ of each analyte. Solutions of ammonium acetate $\left(100 \mathrm{mmol} \mathrm{L}^{-1}, \mathrm{pH}\right)$, sodium acetate $\left(100 \mathrm{mmol} \mathrm{L}^{-1}, \mathrm{pH} 4.9\right)$, and sodium hydroxide $\left(2.5 \mathrm{~mol} \mathrm{~L}^{-1}\right)$ were prepared.

\subsection{Materials}

The Strata X-AW (100 mg, $3 \mathrm{~mL}$ ) solid phase extraction cartridges from Phenomenex (Torrance, CA, USA) were used for sample solidphase extraction (SPE). Vortex mixer was from Velp Scientifica (Usmate, Italy). Centrifuge Biocen22R was from OrtoAlresa (Madrid, Spain). Thermomixer HLC from Ditabis (Pforzheim, Germany). Speed vacuum concentrator (mi Vac) was from Genevac LTD (Ipswich, United Kingdom). SPE 12-position vacuum manifold from Phenomenex (Madrid, Spain). 96-well sample plates (AcquityUPLC $700 \mu \mathrm{L}$ ) were from Waters (Barcelona, Spain). Microplate reader for 96 well plates (Halo LED 96) was from Dynamica Scientific Ltd. (London, United Kingdom).

\subsection{UPLC-MS/MS chromatographic system}

The chromatographic system used consisted of a Waters Acquity UPLC-Xevo TQD system (Milford, MA, USA). The conditions employed were: negative electrospray ionization (ESI-), capillary voltage $3.5 \mathrm{kV}$, source temperature $120^{\circ} \mathrm{C}$, desolvation temperature $300^{\circ} \mathrm{C}$, nitrogen cone, and desolvation gas flows were 25 and $680 \mathrm{Lh}^{-1}$, respectively. Dwell time was set to $5 \mathrm{~ms}$ to ensure a minimum of 10 data points per peak. Separation conditions were selected to achieve appropriate chromatographic retention and resolution by using an Acquity UPLC $\mathrm{BEH} \mathrm{C}_{18}$ column $(2.1 \times 50 \mathrm{~mm}, 1.7 \mu \mathrm{m})$ and pre-column $(2.1 \times 5 \mathrm{~mm})$ from Waters. A binary mobile phase $\mathrm{CH}_{3} \mathrm{OH}(0.01 \% \quad \mathrm{v} / \mathrm{v}$ $\left.\mathrm{CH}_{3} \mathrm{COOH}\right): \mathrm{H}_{2} \mathrm{O}\left(0.01 \% \mathrm{v} / \mathrm{v} \mathrm{CH}_{3} \mathrm{COOH}, \mathrm{pH}\right.$ 3) with gradient elution was used. The flow rate was $0.4 \mathrm{~mL} \mathrm{~min}^{-1}$, the column temperature was $37^{\circ} \mathrm{C}$ and the injection volume was $10 \mu \mathrm{L}$. The gradient started with $30 \% \mathrm{v} / \mathrm{v} \mathrm{CH}_{3} \mathrm{OH}\left(0.01 \% \mathrm{v} / \mathrm{v} \mathrm{CH}_{3} \mathrm{COOH}\right)$ (i.e. channel B) and from 1 to $4.0 \mathrm{~min} \% \mathrm{~B}$ increased up to $90 \%$. Return to initial conditions was achieved at $4.1 \mathrm{~min}$ and conditions were maintained for $3.9 \mathrm{~min}$ for system re-equilibration.

Mass spectrometric detection was carried out by multiple reaction monitoring (MRM). The MS/MS conditions for the detection of the prostaglandins $\left(\mathrm{PGE}_{2}, \mathrm{PGF}_{2 \alpha}\right)$, isoprostanes (2,3-dinor-15-epi-15- $\mathrm{F}_{2 \mathrm{t}^{-}}$ IsoP, $5-\mathrm{F}_{2 \mathrm{t}}$-IsoP, 15-keto-15- $\mathrm{E}_{2 \mathrm{t}}$-IsoP, 15-keto-15- $\mathrm{F}_{2 \mathrm{t}}$-IsoP, $15-\mathrm{E}_{2 \mathrm{t}}$-IsoP, $15-\mathrm{F}_{2 \mathrm{t}}$-IsoP, $15(R)-15-\mathrm{F}_{2 \mathrm{t}}$-IsoP), the deuterated internal standard $\left(\mathrm{PGF}_{2 \alpha}-\mathrm{d}_{4}\right)$, and total IsoPs, IsoFs, NeuroPs and NeuroFs were obtained from previous works employing the same equipment [35,36]. The MS/ MS conditions for the detection of 7(RS)-ST- $\Delta^{8}-11$-dihomo-IsoF, 10epi-10- $\mathrm{F}_{4 \mathrm{t}}$-NeuroP, $\mathrm{d}_{4}-10-e p i-10-\mathrm{F}_{4 \mathrm{t}}$-NeuroP, 17-epi-17- $\mathrm{F}_{2 \mathrm{t}}$-dihomoIsoP, $\quad 17-\mathrm{F}_{2 \mathrm{t}}$-dihomo-IsoP, $17(R S)-10$-epi-SC- $\Delta^{15}-11$-dihomo-IsoF, Ent-7(RS) $-7-\mathrm{F}_{2 \mathrm{t}^{-}}$-dihomo-IsoP, $14(R S)-14-\mathrm{F}_{4 \mathrm{t}^{-}} \mathrm{NeuroP}$, and $4(R S)-\mathrm{F}_{4 \mathrm{t}^{-}}$ NeuroP were established from individual $5 \mu \mathrm{mol} \mathrm{L}^{-1}$ standard solutions by direct infusion in the ESI-MS/MS system. The corresponding MS/MS spectra for these new analytes are shown in Electronic Supplementary material Fig. S2, and the characteristic fragmentations for all the analytes are shown in Electronic Supplementary material Table S3.

The MS/MS acquisition parameters are summarized in Table 1. As can be seen, two MRM transitions per analyte were acquired for quantification and confirmation of 15-keto-15- $\mathrm{E}_{2 \mathrm{t}}$-IsoP, 15-keto-15- $\mathrm{F}_{2 \mathrm{t}^{-}}$ IsoP, $\mathrm{PGE}_{2}, 15-\mathrm{F}_{2 \mathrm{t}}$-IsoP, $\mathrm{PGF}_{2 \alpha}, 17-e p i-17-\mathrm{F}_{2 \mathrm{t}}$-dihomo-IsoP, and 2,3dinor-15-epi-15- $\mathrm{F}_{2 \mathrm{t}}$-IsoP. A single $\mathrm{MRM}$ transition was used for 15(R) $-15-\mathrm{F}_{2 \mathrm{t}}$-IsoP, $15-\mathrm{E}_{2 \mathrm{t}}$-IsoP, 5- $\mathrm{F}_{2 \mathrm{t}}$-IsoP, $7(R S)$-ST- $\Delta^{8}-11$-dihomoIsoF, 10-epi-10- $\mathrm{F}_{4 \mathrm{t}}$-NeuroP, $\mathrm{d}_{4}-10-$ epi-10- $\mathrm{F}_{4 \mathrm{t}}$-NeuroP, $\mathrm{PGF}_{2 \alpha}-\mathrm{d}_{4}, 17-$ 
Table 1

Detection parameters.

\begin{tabular}{|c|c|c|c|c|c|c|}
\hline \multirow[t]{2}{*}{ Analyte } & \multirow[t]{2}{*}{$m / z$ Parent Ion } & \multirow[t]{2}{*}{ Cone $[V]$} & \multicolumn{4}{|c|}{$m / z$ Daughter Ion } \\
\hline & & & Quantification & $\mathrm{CE}[\mathrm{eV}]$ & Confirmation & $\mathrm{CE}[\mathrm{eV}]$ \\
\hline $15(R)-15-\mathrm{F}_{2 \mathrm{t}}-\mathrm{IsoP}$ & 353 & 45 & 193 & 25 & - & - \\
\hline 2,3-dinor-15-epi-15- $\mathrm{F}_{2 \mathrm{t}}$-IsoP & 325 & 45 & 237 & 10 & 137 & 10 \\
\hline 15-keto-15-E Et $^{-I s o P}$ & 349 & 45 & 113 & 20 & 161 & 20 \\
\hline 15-keto-15- $\mathrm{F}_{2 \mathrm{t}}$-IsoP & 351 & 40 & 315 & 15 & 289 & 15 \\
\hline $\mathrm{PGE}_{2}$ & 351 & 40 & 271 & 10 & 189 & 10 \\
\hline $15-\mathrm{E}_{2 \mathrm{t}}$-IsoP & 351 & 40 & 189 & 15 & - & - \\
\hline $15-\mathrm{F}_{2 \mathrm{t}}$-IsoP & 353 & 45 & 193 & 25 & 165 & 25 \\
\hline $\mathrm{PGF}_{2 \alpha}$ & 353 & 45 & 193 & 25 & 165 & 25 \\
\hline $\mathrm{PGF}_{2 \alpha}-\mathrm{d}_{4}$ & 357.5 & 45 & 197.3 & 30 & - & - \\
\hline $7(R S)$-ST- $\Delta^{8}$-11-dihomo-IsoF & 397 & 30 & 201 & 20 & - & - \\
\hline $5-F_{2 t}-I s o P$ & 353 & 40 & 115 & 23 & - & - \\
\hline $10-e p i-10-\mathrm{F}_{4 \mathrm{t}}-$ NeuroP & 377 & 55 & 152.9 & 15 & - & - \\
\hline $\mathrm{d}_{4}-10-e p i-10-\mathrm{F}_{4 \mathrm{t}}-\mathrm{NeuroP}$ & 381.4 & 55 & 157.2 & 15 & - & - \\
\hline 17-epi-17- $\mathrm{F}_{2 \mathrm{t}}$-dihomo-IsoP & 381 & 45 & 221 & 25 & 245 & 25 \\
\hline 17- $\mathrm{F}_{2 \mathrm{t}}$-dihomo-IsoP & 381 & 45 & 363 & 10 & - & - \\
\hline $17(R S)-10-e p i-S C-\Delta^{15}-11$-dihomo-IsoF & 397.4 & 30 & 155 & 22 & - & - \\
\hline Ent $-7(R S)-7-\mathrm{F}_{2 \mathrm{t}}$-dihomo-IsoP & 381.6 & 50 & 193.1 & 35 & - & - \\
\hline $14(R S)-14-\mathrm{F}_{4 \mathrm{t}}-\mathrm{NeuroP}$ & 377 & 50 & 150.8 & 15 & - & - \\
\hline $4(R S)-\mathrm{F}_{4 \mathrm{t}}-\mathrm{NeuroP}$ & 377 & 50 & 271 & 20 & - & - \\
\hline NeuroPs & 377 & 35 & 101 & 20 & - & - \\
\hline IsoPs & 353.2 & 40 & 115 & 20 & - & - \\
\hline NeuroFs & 393 & 35 & 193 & 20 & - & - \\
\hline IsoFs & 369.2 & 45 & 115 & 20 & - & - \\
\hline
\end{tabular}

$\mathrm{F}_{2 \mathrm{t}}$-dihomo-IsoP, 17(RS)-10-epi-SC- $\Delta^{15}-11$-dihomo-IsoF, Ent-7(RS) $-7-\mathrm{F}_{2 \mathrm{t}}$-dihomo-IsoP, $14(R S)-14-\mathrm{F}_{4 \mathrm{t}}$-NeuroP, and $4(R S)-\mathrm{F}_{4 \mathrm{t}}-$ NeuroP due to the lack of suitable additional fragmentation.

\subsection{Sample treatment}

Urine samples were thawed on ice and homogenized, and $5 \mu \mathrm{L}$ of internal standard (IS) solution $\left(\mathrm{PGF}_{2 \alpha}-\mathrm{d}_{4} 10 \mu \mathrm{mol} \mathrm{L}^{-1}\right.$ and $\mathrm{d}_{4}-10$ epi-10- $\mathrm{F}_{4 \mathrm{t}}$-NeuroP $6 \mu \mathrm{mol} \mathrm{L}^{-1}$ ) were added to $1 \mathrm{~mL}$ of sample. In order to remove the glucuronide and sulfate derivatives, the samples were

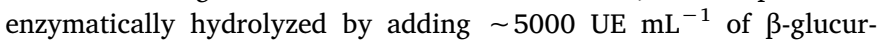
onidase and sodium acetate buffer $\left(250 \mu \mathrm{L}, 100 \mathrm{mmol} \mathrm{L}^{-1}, \mathrm{pH} 4.9\right)$ for $2 \mathrm{~h}$ at $37^{\circ} \mathrm{C}$ [19]. The reactions were stopped and the enzyme was precipitated with $500 \mu \mathrm{L}$ of $\mathrm{MeOH}$ and $8 \mu \mathrm{L}$ of $\mathrm{HCl}(37 \%, v / v)$, then the mixture was centrifuged at $14,000 \mathrm{~g}$ and $4^{\circ} \mathrm{C}$ for $10 \mathrm{~min}$.

Thereafter, the supernatants were adjusted at $\mathrm{pH}$ 6-7 with sodium hydroxide $(2.5 \mathrm{~mol} \mathrm{~L}-1)$ and homogenized. For cleanup and pre-concentration, solid phase extraction (SPE) was carried out. SPE cartridges were conditioned first with $1 \mathrm{~mL} \mathrm{CH} \mathrm{CH}_{3} \mathrm{OH}$ and then with $1 \mathrm{~mL} \mathrm{H}_{2} \mathrm{O}(\mathrm{pH}$ $6-7)$. The diluted sample ( $2 \mathrm{~mL})$ was loaded in the SPE cartridge and it was washed with $1 \mathrm{~mL}$ of ammonium acetate $\left(100 \mathrm{mmol} \mathrm{L}^{-1}, \mathrm{pH} 7\right)$ and $1 \mathrm{~mL}$ of heptane. Elution was carried out with $2 \times 500 \mu \mathrm{L}$ methanol ( $5 \% \mathrm{v} / \mathrm{v}$ acetic acid). Recovered extracts were evaporated and reconstituted in $100 \mu \mathrm{L}$ of $\mathrm{H}_{2} \mathrm{O}(\mathrm{pH} 3): \mathrm{CH}_{3} \mathrm{OH}(85: 15 \mathrm{v} / \mathrm{v})$. Finally, they were injected in the chromatographic system (UPLC-MS/MS).

\subsection{Method validation}

The bioanalytical method validation followed the US Food and Drug Administration (FDA) guidelines [37]. The analytical characteristics assayed during the validation procedure were linearity range, precision, accuracy, selectivity, limit of detection (LOD), limit of quantification (LOQ), carry-over, as well as the stability of analytes. The accuracy was evaluated by means of the recovery test. Urine samples were spiked at three concentration levels, and they were analyzed each validation day $(n=6)$. Also, the non-spiked samples were analyzed each validation day in order to quantify the recoveries. The selectivity was studied by analyzing blanks and non-spiked samples with and without internal standards. The precision was estimated from the analysis of standards and spiked samples at three concentration levels (i.e. low, mid, and high) within one validation batch (intra-day) and among validation batches (inter-day). The LOD and LOQ were established, as the concentrations required generating a signal-to-noise ratio of 3 and 10, respectively. The carry-over was evaluated by the injection of a blank sample after a high concentration sample or standard. Analyte stability in spiked urine samples after three freeze-thaw cycles and the shortterm stability $\left(24 \mathrm{~h}\right.$ at $\left.4{ }^{\circ} \mathrm{C}\right)$ were assessed by comparison with freshly prepared standard solutions.

\subsection{Analysis of urine samples}

Morning urine samples $(\mathrm{n}=18)$ were collected as described above, and kept at $-80^{\circ} \mathrm{C}$ until analysis. The previously described analytical method was applied to these samples. To standardize the results, urinary levels of creatinine were determined using a colorimetric assay kit (MicroVue creatinine EIA) and measuring in a microplate spectrophotometer. In this way, the suitability of the developed method for this kind of samples was assayed, and a first approach to the lipid peroxidation compounds concentrations that can be found in urine samples from patients with MCI-AD and mild dementia-AD was established.

\subsection{Statistical analysis}

Data analysis was carried out using the Unscrambler 7.6 (Camo, Woodbridge, USA) software. A multivariable regression model based on the oxidative stress biomarkers levels is described to discriminate among healthy, MCI-AD, and mild dementia-AD participants. It consists of partial least squares (PLS). The PLS model was constructed with 21 independent variables (predictors), and 1 dependent variable (response). All the variables were centred and predictors were also autoscaled. The cross validation was used to validate the model. The predictive ability of the model is expressed by the percentage of validation explained variance.

Univariate statistical analyses were performed using SPSS version 20.0 software (SPSS, Inc., Chicago, IL, USA). For all analyses, the statistical significance was set at $p<0.05$. Data were presented as mean \pm standard deviation (SD), median (inter-quartile range, IQR) or number of cases (n) and percentage (\%). Kolmogorov-Smirnov test was 
used to test for normal distribution of the data. For comparison of some biomarkers concentrations, nonparametric methods were used. KruskalWallis tests were performed to compare medians among 3 groups, and Mann Whitney tests to compare medians between 2 groups.

\section{Results and discussion}

\subsection{Sample treatment optimization}

Several parameters involved in the urine samples treatment to determine the selected lipid peroxidation biomarkers were optimized. First, internal standards were selected taking into account their physical-chemical characteristics (retention time, polarity, structure). Among the different available deuterated compounds, $\mathrm{PGF}_{2 \alpha}-\mathrm{d}_{4}$ and $\mathrm{d}_{4}-10-e p i-10-\mathrm{F}_{4 \mathrm{t}}$-NeuroP, accomplished the similarity requirements compared to most of the analytes $\left(\mathrm{F}_{2}\right.$-IsoPs, and $\mathrm{F}_{4}$-NeuroPs, respectively), and they were selected for further work. They were added in the first step of sample treatment procedure in order to minimize all the experimental errors.

Secondly, several types of SPE cartridges were assayed to carry out urine sample clean-up and analytes preconcentration. They were based on reversed phase (C18-endcapped, C18-not endcapped, polymeric) and weak anion exchange and reversed phase $\left(\mathrm{NH}_{2}\right.$, polymeric). The results showed that a mix mode SPE based on weak anion exchange and reversed phase provided better recoveries with a 10-factor preconcentration (data not shown).

Thirdly, some SPE conditions (sample $\mathrm{pH}$, clean-up solvents, elution solvent, and elution volume) were assayed to obtain higher recoveries. The optimum conditions selected were sample at $\mathrm{pH} 7$, a two-step cartridge clean-up with ammonium acetate solution and heptane, and an elution step with $1 \mathrm{~mL}$ of methanol containing acetic acid at $5 \% \mathrm{v} / \mathrm{v}$.

\subsection{Analytical performance data}

The reliability of the described method was evaluated by employing standards that contained the analytes in the $0.03-300 \mathrm{nmol} \mathrm{L}^{-1}$ concentration range. As shown in Electronic Supplementary material Table S4, the method provided an adequate linearity for all the analytes within the corresponding concentrations ranges, and $\mathrm{R}^{2}$ ranged between 0.98 and 0.993 . The method also provided suitable precision, with intra-day and inter-day coefficients of variation of $5-17 \%(n=5)$ and $8-19 \%(n=6)$, respectively (at medium concentration level within the linearity interval). The higher irreproducibility corresponded to compounds with lower sensitivity $\left(14(R S)-14-\mathrm{F}_{4 \mathrm{t}}\right.$-NeuroP, Ent$7(R S)-7-\mathrm{F}_{2 \mathrm{t}}$-dihomo-IsoP) or poor chromatographic resolution (17epi-17- $\mathrm{F}_{2 \mathrm{t}}$-dihomo-IsoP, $\mathrm{PGE}_{2}$ ). Also in Table S4 (Electronic Supplementary material), we can see the instrumental LODs obtained for each analyte, they were between 0.08 and $17 \mathrm{nmol} \mathrm{L}^{-1}$. LODs obtained were suitable to detect these analytes in urine human samples, and similar to those previously reported in literature $[17,27]$. The LOQs were between 0.15 and $35 \mathrm{nmol} \mathrm{L}^{-1}$.

The accuracy of the method was evaluated by analyzing standard solutions containing analytes at different concentrations within the tested concentration ranges. The results obtained are listed at Table 2. In all instances, the proposed method provided values close to the real concentrations. In general, the lowest concentrations showed higher irreproducibility. In addition, quantitative recoveries for urine samples spiked at different concentration levels (low, medium and high) were achieved for most of the analytes (Table 2), only a few of them (15- $\mathrm{E}_{2 \mathrm{t}^{-}}$ IsoP, 17- $\mathrm{F}_{2 \mathrm{t}}$-dihomo-IsoP, $17(R S)-10$-epi-SC- $\Delta^{15}-11$-dihomo-IsoF, $7(R S)$-ST- $\Delta^{8}$-11-dihomo-IsoF) showed recoveries below $80 \%$ or above $120 \%$. Matrix effect was evaluated by using a linear regression model to compare the concentrations obtained for each analyte in spiked urine samples using the proposed method $(\mathrm{Y})$ with the added concentrations (X). For all the analytes, slopes were statistically comparable to 1 , so matrix effect was not observed at 5\% significance level in any analyte.
Carry over in the blank sample following the high concentration standard was lower than $10 \%$ of the lower limit of quantification.

As regards total parameters (IsoPs, IsoFs, NeuroPs, NeuroFs), relative contents were determined in urine samples from participants.

\subsection{Analyte stability study}

The analytes' stability was assayed at long-term (after one, two, or three freeze-thaw cycles) and at short-term $\left(24 \mathrm{~h}\right.$ at $\left.4{ }^{\circ} \mathrm{C}\right)$. This study was carried out determining the concentrations in a spiked urine sample (at medium concentration level in the interval concentrations) by triplicate. Then, these concentrations were compared to freshly prepared standard solutions. As shown in Electronic Supplementary materialTable S5 the recoveries were between $72 \%$ and $130 \%$. Hence, no significant deterioration of the analytes was observed.

\subsection{Application to urine samples}

The reliability of the validated method was tested analyzing 18 urine samples by triplicate. These samples were from healthy, MCI-AD, and mild dementia-AD patients. The analytes $15(R)-15-\mathrm{F}_{2 \mathrm{t}^{-}}-\mathrm{IsoP}, 5-\mathrm{F}_{2 \mathrm{t}^{-}}$ IsoP, 17- $\mathrm{F}_{2 \mathrm{t}}$-dihomo-IsoP, PGF $_{2 \alpha}, 2$,3-dinor-15-epi-15- $\mathrm{F}_{2 \mathrm{t}}$-IsoP, and $4(R S)-\mathrm{F}_{4 \mathrm{t}}-$ NeuroP were detected in all the samples, indicating the satisfactory sensitivity of the developed method to analyze real samples. However, in a previous work, only $\mathrm{F}_{2 \mathrm{t}}$-dihomo-IsoPs were detected in urine samples from healthy elderly people, reflecting not enough sensitivity to detect $\mathrm{F}_{4}$-NeuroPs [38]. Also, total parameters were found above the LOD (a signal-to-noise ratio of 3), showing changes in the relative levels of IsoPs, IsoFs, NeuroPs, and NeuroFs among the analyzed samples. The values are listed in Table 3. Chromatograms obtained for some analytes $\left(15(R)-15-\mathrm{F}_{2 \mathrm{t}}-\mathrm{Iso}\right.$, $\mathrm{PGF}_{2 \alpha}, 2,3$-dinor-15$e p i-15-\mathrm{F}_{2 \mathrm{t}}-\mathrm{IsoP}, \mathrm{PGE}_{2}$ ) and total parameters (neuroprostanes, isoprostanes) from the analysis of participants urine samples are shown in Fig. 1.

\subsection{Statistical analysis}

Due to the low number of samples analyzed, the PLS model allows us to carry out a preliminary study of correlations between predictor variables (biomarkers levels) and response variable (control, MCI-AD, mild dementia-AD), as well as an approximate classification of participants. This model was considered satisfactory in terms of predictive ability.

In this model, 21 independent variables (17 individual biomarkers, 4 total parameters) are spatially distributed in order to improve the separation among the 3 groups of participants $(0=$ control, $1=$ MCI$\mathrm{AD}, 2$ =mild-dementia-AD). Fig. S3 in Electronic Supplementary material shows that explained variance was around $80 \%$ with 3 principal components (PC). Therefore, the maximum number of latent variables selected was 3. In the loadings plot (Fig. S4a in Electronic Supplementary material) we observed that the PC1 correlated with the response variable (group), as well as with 15-keto- $15-\mathrm{F}_{2 \mathrm{t}}$-IsoP, 2,3dinor-15-epi-15- $\mathrm{F}_{2 \mathrm{t}}$-IsoP, $15-\mathrm{F}_{2 \mathrm{t}}$-IsoP and $15-\mathrm{E}_{2 \mathrm{t}}$-IsoP. This suggested that these variables varied together and increased with the PC1. However, an inverse correlation was observed along PC1 between the response variable (group) and some biomarkers (10-epi-10- $\mathrm{F}_{4 \mathrm{t}^{-}}$ NeuroP, 17(RS)-10-epi-SC- $\Delta_{15}-11$-dihomo-IsoF, PGE 2 ) and total parameters (IsoF, IsoP, NeuroP). Therefore, this component might be considered a measure of the AD diagnostic. As regards the scores plot obtained from PC2 vs PC1, a separation of the 3 participants groups was achieved (Fig. S4b in Electronic Supplementary material). Specifically, healthy and mild dementia-AD participants could be classified correctly, but the MCI-AD group separation was less evident.

In order to confirm previous results in multivariable analysis, univariate statistical analysis was carried out. For this, nonparametric methods were used as the variables were not normally distributed. A 
Table 2

Accuracy and precision of standard solutions and recoveries obtained from the analysis of spiked urine samples at different concentration levels.

\begin{tabular}{|c|c|c|c|c|c|c|}
\hline \multirow{3}{*}{ Analytes } & \multicolumn{3}{|l|}{ Standard Solutions } & \multicolumn{3}{|l|}{ Spiked urine samples } \\
\hline & \multirow{2}{*}{$\begin{array}{l}\text { Standard concentration } \\
(\mathrm{nmol} \mathrm{L} \\
-1)\end{array}$} & \multicolumn{2}{|c|}{$[$ Recovery $\pm s(\%)]$} & \multirow{2}{*}{$\begin{array}{l}\text { Sample added concentration } \\
\left(\mathrm{nmol} \mathrm{L}^{-1}\right)\end{array}$} & \multicolumn{2}{|c|}{$[$ Recovery $\pm \mathrm{s}(\%)]$} \\
\hline & & $\begin{array}{l}\text { Intra-day } \\
(n=5)\end{array}$ & $\begin{array}{l}\text { Inter-day } \\
(\mathrm{n}=6)\end{array}$ & & $\begin{array}{l}\text { Intra-day } \\
(\mathrm{n}=3)\end{array}$ & Inter-day $(n=6)$ \\
\hline \multirow[t]{3}{*}{ 2,3-dinor-15-epi-15- $\mathrm{F}_{2 \mathrm{t}}$-IsoP } & 18.75 & $108 \pm 20$ & $120 \pm 20$ & 1.87 & $110 \pm 17$ & $120 \pm 10$ \\
\hline & 75 & $105 \pm 8$ & $99 \pm 12$ & 7.5 & $92 \pm 19$ & $112 \pm 7$ \\
\hline & 150 & $97 \pm 19$ & $104 \pm 20$ & 15 & $102 \pm 3$ & $115 \pm 5$ \\
\hline \multirow[t]{3}{*}{ 15-keto-15- $\mathrm{F}_{2 \mathrm{t}}$-IsoP } & 18.75 & $120 \pm 5$ & $92 \pm 8$ & 1.87 & $96 \pm 11$ & $112 \pm 14$ \\
\hline & 75 & $87 \pm 7$ & $83 \pm 16$ & 7.5 & $121 \pm 5$ & $118 \pm 19$ \\
\hline & 150 & $95 \pm 14$ & $120 \pm 10$ & 15 & $86 \pm 5$ & $118 \pm 17$ \\
\hline \multirow{3}{*}{ 15-keto-15-E $\mathrm{E}_{2 \mathrm{t}}$-IsoP } & 18.75 & $115 \pm 12$ & $117 \pm 20$ & 1.87 & $109 \pm 9$ & $109 \pm 19$ \\
\hline & 75 & $122 \pm 8$ & $83 \pm 14$ & 7.5 & $115 \pm 9$ & $121 \pm 12$ \\
\hline & 150 & $102 \pm 8$ & $108 \pm 13$ & 15 & $102 \pm 12$ & $95 \pm 13$ \\
\hline \multirow{3}{*}{$15(R)-15-\mathrm{F}_{2 \mathrm{t}}$-IsoP } & 18.75 & $107 \pm 18$ & $106 \pm 15$ & 1.87 & $120 \pm 20$ & $109 \pm 20$ \\
\hline & 75 & $97 \pm 7$ & $94 \pm 8$ & 7.5 & $85 \pm 20$ & $87 \pm 19$ \\
\hline & 150 & $83 \pm 3$ & $92 \pm 20$ & 15 & $104 \pm 9$ & $102 \pm 18$ \\
\hline \multirow[t]{3}{*}{$\mathrm{PGE}_{2}$} & 18.75 & $111 \pm 19$ & $112 \pm 20$ & 1.87 & $119 \pm 9$ & $120 \pm 20$ \\
\hline & 75 & $91 \pm 16$ & $90 \pm 16$ & 7.5 & $95 \pm 20$ & $100 \pm 20$ \\
\hline & 150 & $88 \pm 10$ & $100 \pm 20$ & 15 & $101 \pm 13$ & $110 \pm 20$ \\
\hline \multirow[t]{3}{*}{$15-\mathrm{E}_{2 \mathrm{t}}$-IsoP } & 18.75 & $115 \pm 19$ & $100 \pm 20$ & 1.87 & $106 \pm 20$ & $95 \pm 20$ \\
\hline & 75 & $109 \pm 11$ & $100 \pm 19$ & 7.5 & $70 \pm 12$ & $69 \pm 14$ \\
\hline & 150 & $108 \pm 7$ & $111 \pm 7$ & 15 & $79 \pm 7$ & $77 \pm 6$ \\
\hline \multirow[t]{3}{*}{$15-\mathrm{F}_{2 \mathrm{t}}$-IsoP } & 18.75 & $80 \pm 18$ & $84 \pm 19$ & 1.87 & $90 \pm 20$ & $100 \pm 20$ \\
\hline & 75 & $94 \pm 11$ & $96 \pm 13$ & 7.5 & $79 \pm 9$ & $88 \pm 12$ \\
\hline & 150 & $121 \pm 5$ & $120 \pm 12$ & 15 & $108 \pm 13$ & $114 \pm 17$ \\
\hline \multirow[t]{3}{*}{$\mathrm{PGF}_{2 \alpha}$} & 18.75 & $120 \pm 10$ & $111 \pm 11$ & 1.87 & $111 \pm 18$ & $107 \pm 6$ \\
\hline & 75 & $102 \pm 7$ & $96 \pm 15$ & 7.5 & $80 \pm 10$ & $105 \pm 20$ \\
\hline & 150 & $97 \pm 19$ & $101 \pm 17$ & 15 & $111 \pm 9$ & $120 \pm 17$ \\
\hline \multirow[t]{3}{*}{$4(R S)-\mathrm{F}_{4 \mathrm{t}}-\mathrm{NeuroP}$} & 17.7 & $112 \pm 18$ & $102 \pm 20$ & 1.77 & $104 \pm 14$ & $89 \pm 19$ \\
\hline & 71 & $95 \pm 5$ & $94 \pm 17$ & 7.09 & $98 \pm 4$ & $102 \pm 12$ \\
\hline & 141.9 & $109 \pm 16$ & $99 \pm 18$ & 14.19 & $92 \pm 16$ & $94 \pm 13$ \\
\hline \multirow[t]{3}{*}{$7(R S)$-ST- $\Delta^{8}-11$-dihomo-IsoF } & 16.9 & $81 \pm 11$ & $84 \pm 20$ & 1.69 & $119 \pm 5$ & $122 \pm 9$ \\
\hline & 67.6 & $120 \pm 15$ & $101 \pm 19$ & 6.76 & $78 \pm 10$ & $75 \pm 15$ \\
\hline & 135.2 & $98 \pm 13$ & $96 \pm 11$ & 13.52 & $74 \pm 7$ & $75 \pm 11$ \\
\hline \multirow[t]{3}{*}{$5-\mathrm{F}_{2 \mathrm{t}}-\mathrm{IsoP}$} & 18.8 & $119 \pm 20$ & $115 \pm 13$ & 1.88 & $79 \pm 4$ & $80 \pm 10$ \\
\hline & 75.2 & $106 \pm 5$ & $115 \pm 20$ & 7.52 & $115 \pm 5$ & $117 \pm 9$ \\
\hline & 150.3 & $87 \pm 8$ & $85 \pm 19$ & 15.03 & $95 \pm 12$ & $110 \pm 20$ \\
\hline \multirow[t]{3}{*}{$10-e p i-10-\mathrm{F}_{4 \mathrm{t}}-\mathrm{NeuroP}$} & 17.7 & $104 \pm 11$ & $97 \pm 18$ & 1.77 & $123 \pm 12$ & $130 \pm 20$ \\
\hline & 70.9 & $89 \pm 8$ & $96 \pm 9$ & 7.09 & $120 \pm 19$ & $116 \pm 20$ \\
\hline & 141.9 & $97 \pm 3$ & $102 \pm 7$ & 14.19 & $120 \pm 14$ & $123 \pm 19$ \\
\hline 17-epi-17- $\mathrm{F}_{2 \mathrm{t}}$-dihomo-IsoP & 17.6 & $99 \pm 20$ & $80 \pm 16$ & 1.76 & $100 \pm 10$ & $110 \pm 4$ \\
\hline & 70.3 & $77 \pm 13$ & $77 \pm 14$ & 7.03 & $80 \pm 20$ & $70 \pm 5$ \\
\hline & 140.7 & $115 \pm 10$ & $105 \pm 19$ & 14.07 & $85 \pm 14$ & $71 \pm 6$ \\
\hline 17-F $\mathrm{F}_{2 \mathrm{t}}$-dihomo-IsoP & 17.5 & $119 \pm 8$ & $111 \pm 20$ & 1.75 & $130 \pm 11$ & $130 \pm 16$ \\
\hline & 70.0 & $113 \pm 8$ & $98 \pm 10$ & 7.00 & $81 \pm 5$ & $96 \pm 18$ \\
\hline & 140.1 & $108 \pm 10$ & $108 \pm 10$ & 14.01 & $107 \pm 12$ & $108 \pm 15$ \\
\hline $17(R S)-10-e p i-S C-\Delta^{15}-11-$ & 16.9 & $77 \pm 6$ & $74 \pm 20$ & 1.69 & $120 \pm 30$ & $130 \pm 30$ \\
\hline dihomo-IsoF & 67.6 & $84 \pm 8$ & $75 \pm 8$ & 6.76 & $101 \pm 20$ & $101 \pm 20$ \\
\hline & 135.3 & $98 \pm 6$ & $92 \pm 13$ & 13.52 & $130 \pm 4$ & $132 \pm 19$ \\
\hline Ent $-7(R S)-7-\mathrm{F}_{2 \mathrm{t}}$-dihomo-IsoP & 17.6 & - & - & 1.76 & - & - \\
\hline & 70.3 & $118 \pm 12$ & $106 \pm 19$ & 7.03 & $113 \pm 20$ & $78 \pm 14$ \\
\hline & 140.7 & $120 \pm 19$ & $119 \pm 20$ & 14.07 & $114 \pm 4$ & $104 \pm 18$ \\
\hline $14(R S)-14-\mathrm{F}_{4 \mathrm{t}}-$ NeuroP & 17.7 & - & & 1.77 & - & \\
\hline & 70.9 & $111 \pm 14$ & $105 \pm 19$ & 7.09 & $86 \pm 4$ & $78 \pm 12$ \\
\hline & 141.9 & $118 \pm 20$ & $110 \pm 19$ & 14.19 & $108 \pm 10$ & $96 \pm 20$ \\
\hline
\end{tabular}

comparison of each analyte among groups using Kruskall-Wallis test revealed that the medians for NeuroP $(p=0.017)$, IsoP $(p=0.010)$, IsoF $(p=0.013)$, and $\mathrm{PGE}_{2}(p=0.029)$ were significantly different among groups (Table 3 ). Also, the comparison of each analyte between each two groups of participants using Mann Whitney test indicated that medians were different between control and MCI-AD groups for $\mathrm{PGE}_{2}$ and NeuroP, and between control and mild dementia-AD groups for NeuroP, IsoP, and IsoF. Therefore, $\mathrm{PGE}_{2}$ and NeuroP can be considered potential $\mathrm{AD}$ biomarkers at MCI phase, while IsoP and IsoF can be potential AD biomarkers at mild dementia phase. These differences can be explained by the different origin of these molecules. In fact, $\mathrm{PGE}_{2}$ is generated by the action of cyclooxygenase enzymes and its function is related to inflammation [39], while the other compounds derived from lipid peroxidation by free radicals. Specifically, IsoP and IsoF derived from arachidonic acid, and NeuroP derived from docosahexaenoic acid (abundant in brain grey matter) [11]. No statistically significant differences were obtained for the other compounds. In Fig. 2 we can see that for some biomarkers obtained by free-radical mediated oxidation (NeuroP, IsoP, IsoF, 17(RS) - 10-epi-SC- $\Delta^{15}-11$-dihomo-IsoF) their levels decreased along the disease as it was observed in the multivariable regression model. It could be explained by the temporary nature of some oxidized metabolites, which continue their oxidation towards other compounds of lower molecular weight along the disease development [40]. Another explanation could be the overexpression of antioxidant enzymes in patients at early $\mathrm{AD}$ stages, it would be corroborated by previous studies showing that individuals at risk of $\mathrm{AD}$ may suffer reductive stress [41]. 
Table 3

Results obtained from the analysis of urine samples $(n=18)$.

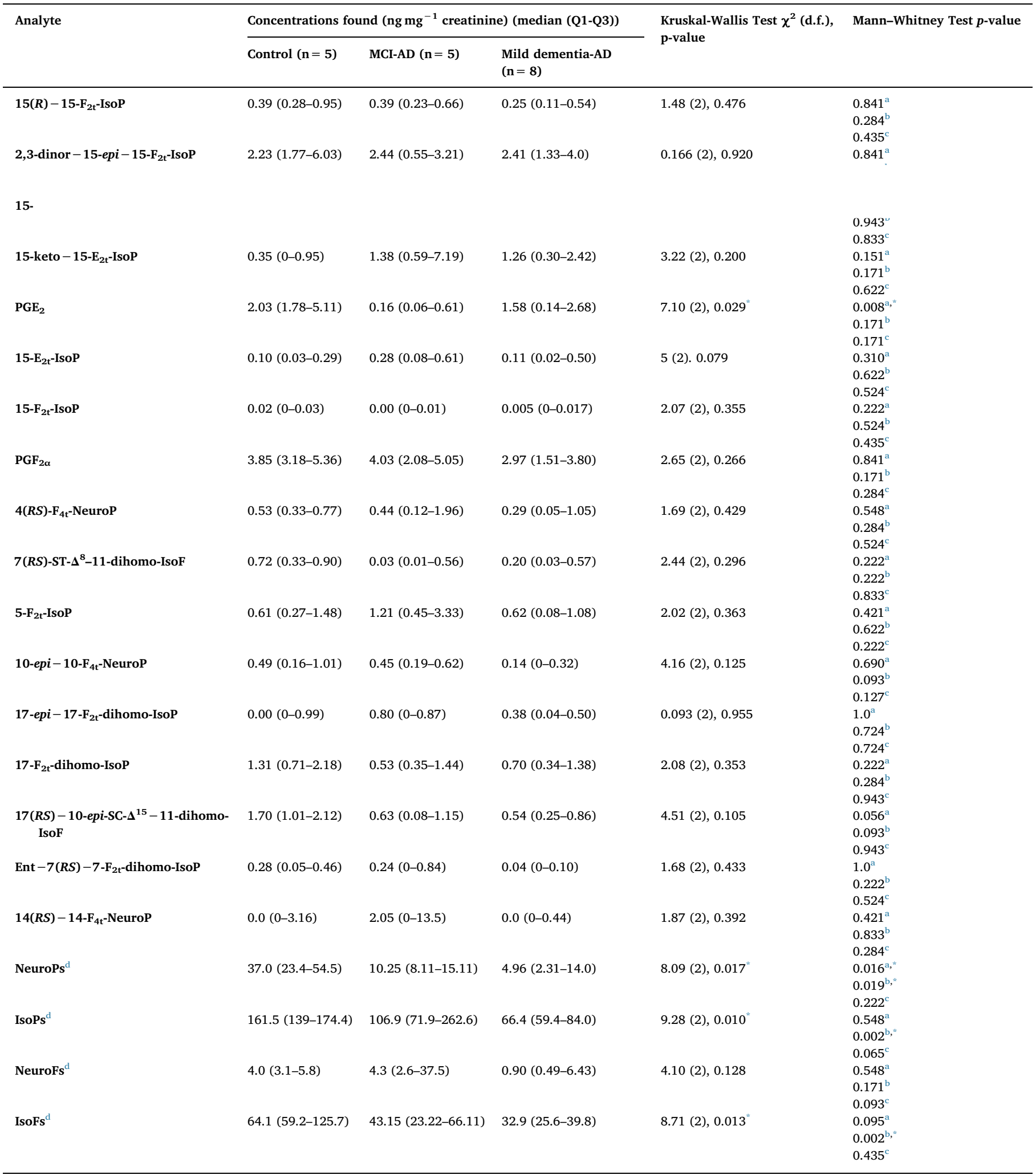

Q1: quartile 1; Q3: quartile 3 .

$* \mathrm{P}<0.05$.

${ }^{a}$ Comparison between control and MCI-AD groupsgroups.

b Comparison between control and mild dementia-AD groups.

c Comparison between MCI-AD and mild dementia-AD groups.

${ }^{\mathrm{d}}$ Total parameters results are expressed as (intensity of signal units $\mathrm{x}$ (internal standard concentration, $\mathrm{mg} \mathrm{L}^{-1}$ )) $\mathrm{mg}^{-1}$ of creatinine. 
(a)
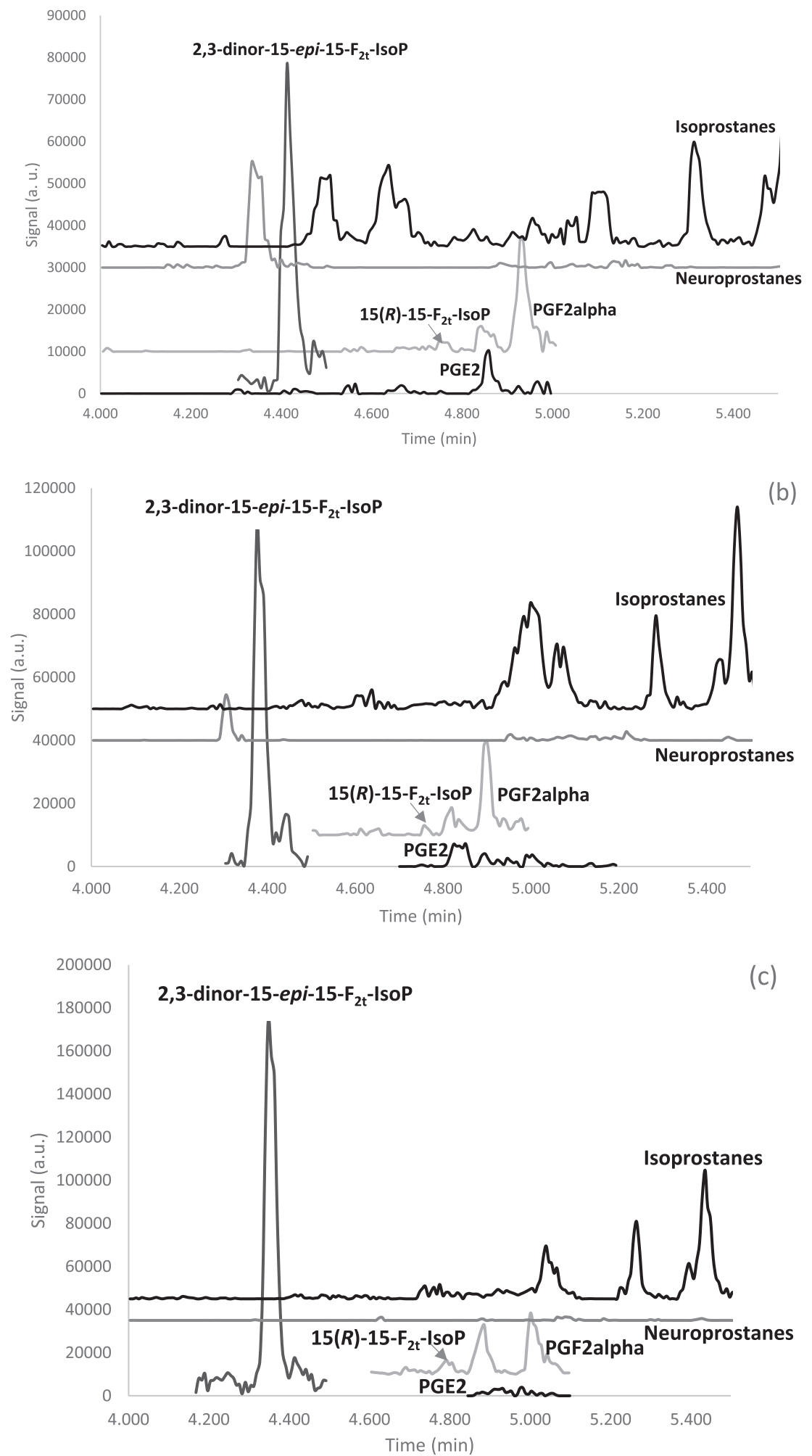

Fig. 1. Chromatograms obtained from urine samples analysis for: (a) control participants, (b) MCI-AD patients, and (c) mild dementia-AD patients.

\section{Conclusions}

The present work describes a reliable and sensitive UPLC-MS/MS method for the simultaneous determination of 17 analytes $\left(\mathrm{F}_{2}\right.$-IsoPs, prostaglandins, $\mathrm{F}_{4}$-NeuroPs, $\mathrm{F}_{2}$-dihomo-IsoPs, dihomo-IsoFs) and 4 total parameters (IsoP, NeuroP, IsoF, NeuroF) in urine samples. Of note, most of these analytes have not been measured in previous works found in literature $[38,42]$, and the lack of validated liquid chromatographic methods to determine these new set of lipid peroxidation biomarkers in urine human samples adds relevance to this new method. The described UPLC-MS/MS method can be considered a simple alternative to previously published methods, which employ chemical derivatization and gas chromatography.

The developed method provided suitable accuracy, sensitivity, and 

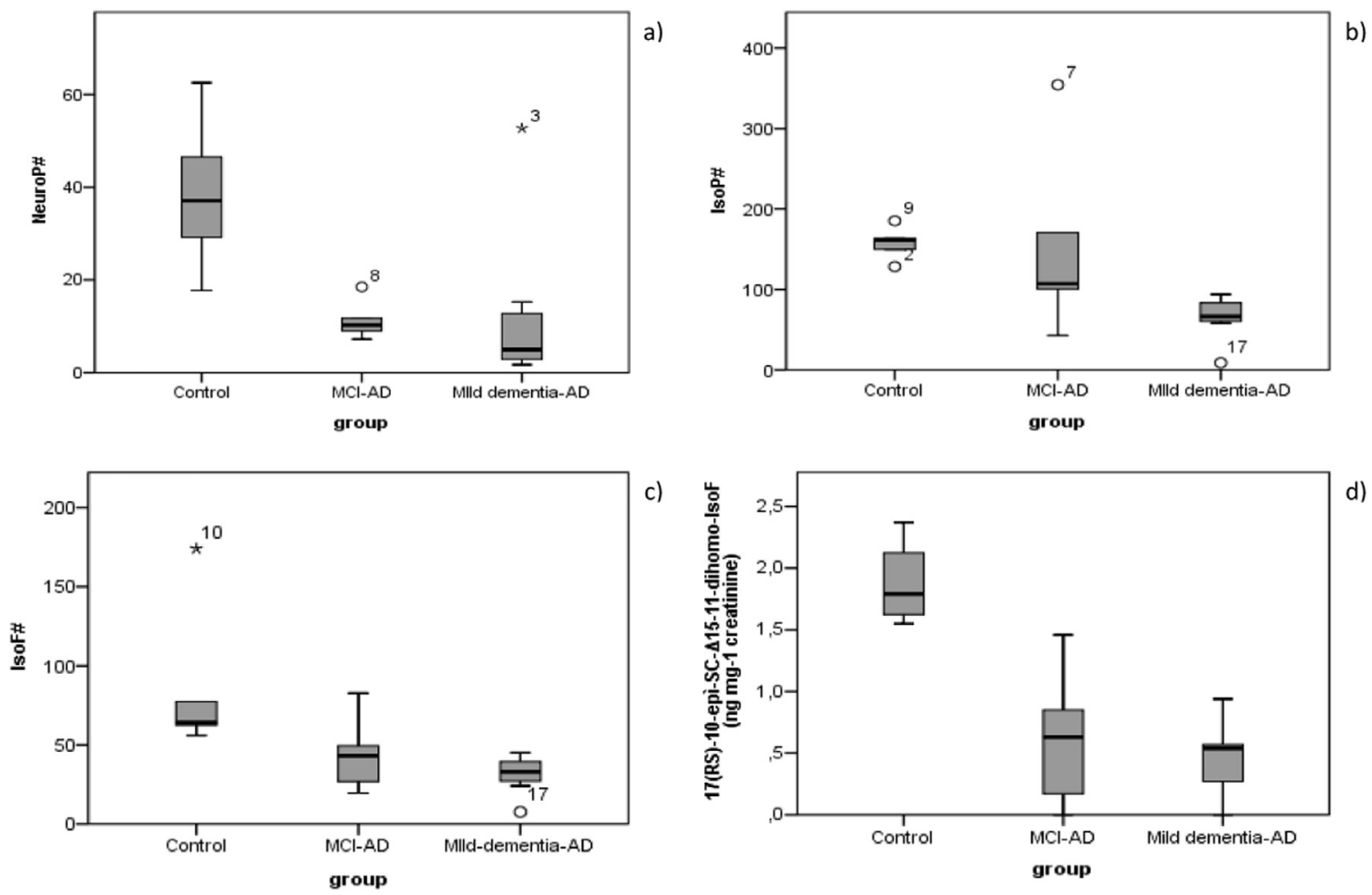

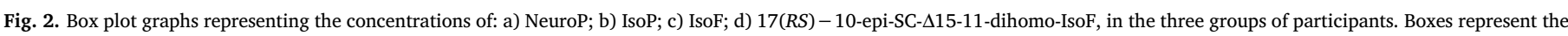

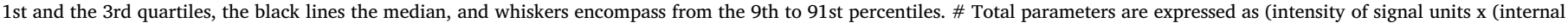
standard concentration, $\mathrm{mg} \mathrm{L}^{-1}$ )) $\mathrm{mg}^{-1}$ of creatinine.

high throughput to be applied to urine samples from MCI and mild dementia $\mathrm{AD}$ patients. Some analytes showed statistically significant lower concentrations for the MCI-AD and mild dementia-AD groups. Nevertheless, further analysis employing the developed analytical method and a greater number of samples is required to corroborate these preliminary results. Therefore, the described analytical method constitutes a useful tool for subsequent clinical studies in order to validate these compounds as potential early AD biomarkers.

\section{Acknowledgment}

We are greatly indebted to all participants, nursing and medical staff who voluntarily participated in the present study. Without their collaboration and enthusiasm this study could not have been completed.

CC-P acknowledges a "Miguel Servet I" Grant (CP16/00082) from the ISCIII (Spanish Ministry of Economy and Competitiveness). MV acknowledges RETICS funded by the PN 2018-2011 (Spain), ISCIIISub-Directorate General for Research Assessment and Promotion and the European Regional Development Fund (FEDER), reference RD12/ 0026; AG-B acknowledges a post-doctoral Grant (associated to "Miguel Servet" project CP16/00082) from the Instituto Carlos III (Spanish Ministery of Economy and Competitiveness).

\section{Conflict of interest}

The authors report no conflict of interest.

\section{Funding}

This work was supported by "Miguel Servet I" Project (CP16/ 00082) from the ISCIII (Spanish Ministry of Economy and Competitiveness), and RETICS funded by the PN 2018-2011 (Spain), ISCIII- Sub-Directorate General for Research Assessment and Promotion and the European Regional Development Fund (FEDER), reference $\mathrm{RD} 12 / 0026$.

\section{Appendix A. Supporting information}

Supplementary data associated with this article can be found in the online version at http://dx.doi.org/10.1016/j.talanta.2018.03.002.

\section{References}

[1] S. Chen, S.P. Yadav, W.K. Surewicz, Interaction between human prion protein and amyloid-beta (Abeta) oligomers: role of N-terminal residues, J. Biol. Chem. 285 (2010) 26377-26383.

[2] J.L. Molinuevo, K. Blennow, B. Dubois, S. Engelborghs, P. Lewczuk, A. PerretLiaudet, C.E. Teunissen, L. Parnetti, The clinical use of cerebrospinal fluid biomarker testing for Alzheimer's disease diagnosis: a consensus paper from the Alzheimer's Biomarkers Standardization Initiative, Alzheimers Dement. 10 (2014) 808-817.

[3] J.B. Toledo, H. Zetterberg, A.C. van Harten, L. Glodzik, P. Martinez-Lage, L. Bocchio-Chiavetto, L. Rami, O. Hansson, R. Sperling, S. Engelborghs, R.S. Osorio, H. Vanderstichele, M. Vandijck, H. Hampel, S. Teipl, A. Moghekar, M. Albert, W.T. Hu, J.A. Monge Argilés, A. Gorostidi, C.E. Teunissen, P.P. De Deyn, B.T. Hyman, J.L. Molinuevo, G.B. Frisoni, G. Linazasoro, M.J. de Leon, W.M. van der Flier, P. Scheltens, K. Blennow, L.M. Shaw, J.Q. Trojanowski, Alzheimer's disease cerebrospinal fluid biomarker in cognitively normal subjects, Brain 138 (2015) 2701-2715.

[4] C. Cervellati, A. Romani, D. Seripa, E. Cremonini, C. Bosi, S. Magon, C.M. Bergamini, G. Valacchi, A. Pilotto, G. Zuliani, Systemic oxidative stress and conversion to dementia of elderly patients with mild cognitive impairment, Biomed. Res. Int. (2014) 309507.

[5] M.C. Puertas, J.M. Martínez-Martos, M.P. Cobo, M.P. Carrera, M.D. Mayas, M.J. Ramírez-Expósito, Plasma oxidative stress parameters in men and women with early stage Alzheimer type dementia, Exp. Gerontol. 47 (2012) 625-630.

[6] D.A. Loeffler, A.C. Klaver, M.P. Coffey, J.O. Aasly, P.A. LeWitt, Increased oxidative stress markers in cerebrospinal fluid from healthy subjects with Parkinson's Diseaseassociated LRRK2 gene mutations, Front. Aging Neurosci. 9 (2017) 1-8.

[7] M. Singh, T.N. Dang, M. Arseneault, C. Ramassamy, Role of by-products of lipid oxidation in Alzheimer's disease brain: a focus on acrolein, J. Alzheimers Dis. 21 (2010) 741-756.

[8] A. García-Blanco, M. Baquero, M. Vento, E. Gil, L. Bataller, C. Cháfer-Pericás, Potential oxidative stress biomarkers of mild cognitive impairment due to Alzheimer disease, J. Neurol. Sci. 373 (2017) 295-302. 
[9] T.T. Reed, Lipid peroxidation and neurodegenerative disease, Free Radic. Biol. Med. 51 (2011) 1302-1319.

[10] I. Suridjan, N. Herrmann, A. Adibfar, M. Saleem, A. Andreazza, P.I. Oh, K.L. Lanctôt, Lipid peroxidation markers in coronary artery disease patients with possible vascular mild cognitive impairment, J. Alzheimer Dis. (2017) 1-12.

[11] E. Miller, A. Morel, L. Saso, J. Saluk, Isoprostanes and neuroprostanes as biomarkers of oxidative stress in neurodegenerative diseases, Oxid. Med. Cell Longev. (2014) $1-10$.

[12] M.A. Bradley-Whitman, M.A. Lovell, Biomarkers of lipid peroxidation in Alzheimer disease (AD): an update, Arch. Toxicol. 89 (2015) 1035-1044.

[13] D. Praticò, C.M. Clark, F. Liun, J. Rokach, V. Lee, Y. Trojanowski, Increase of brain oxidative stress in mild cognitive impairment: a possible predictor of Alzheimer disease, Arch. Neurol. 59 (2002) 972-976.

[14] T.J. Montine, J. Quinn, J. Kaye, J.D. Morrow, F(2)-isoprostanes as biomarkers of late-onset Alzheimer's disease, J. Mol. Neurosci. 33 (2007) 114-119.

[15] M. Czerska, M. Zieliński, J. Gromadzińska, Isoprostanes - A novel major group of oxidative stress markers, Int. J. Occup. Med. Environ. Health 29 (2016) 179-190.

[16] J. Aszyk, J. Kot, Y. Tkachenko, M. Woźniak, A. Bogucka-Kocka, A. Kot-Wasik, Novel liquid chromatography method based on linear weighted regression for the fast determination of isoprostane isomers in plasma samples using sensitive tandem mass spectrometry detection, J. Chromatogr. B Anal. Technol. Biomed. Life Sci. 1051 (2017) 17-23.

[17] A. Dupuy, P. Le Faouder, C. Vigor, C. Oger, J.M. Galano, C. Dray, J.C. Lee, P. Valet, C. Gladine, T. Durand, J. Bertrand-Michel, Simultaneous quantitative profiling of 20 isoprostanoids from omega- 3 and omega- 6 polyunsaturated fatty acids by LC-MS/ MS in various biological samples, Anal. Chim. Acta 921 (2016) 46-58.

[18] S. Medina, M. Elízaga, C. Oger, J.M. Galano, T. Durand, M. Martínez-Villanueva, M.L. Castillo, I. Villegas-Martínez, F. Ferreres, P. Martínez-Hernández, A. GilIzquierdo, Dihomo-isoprostanes-nonenzymatic metabolites of AdA-are higher in epileptic patients compared to healthy individuals by a new ultrahigh pressure liquid chromatography-triple quadrupole-tandem mass spectrometry method, Free Radic. Biol. . Med. 79 (2015) 154-163.

[19] S. Medina, R. Domínguez-Perles, R. Cejuela-Anta, D. Villaño, J.M. Martínez-Sanz, P. Gil, C. García-Viquera, F. Ferreres, J.I. Gil, A. Gil-Izquierdo, Assessment of oxidative stress markers and prostaglandins after chronic training of triathletes, Prostaglandins Other Lipid Mediat. 99 (2012) 79-86.

[20] C. Sabanayagam, W.K. Lye, A. Januszewski, R.B.B.M. Abdul, G.C.M. Cheung, N. Kumari, T.Y. Wong, C.Y. Cheng, E. Lamoureux, Urinary isoprostane levels and age-related macular degeneration, Investig. Ophtalmol. Vis. Sci. 58 (2017) 2538-2543.

[21] D. Tsikas, M.T. Suchy, Protocols for the measurement of the F2-isoprostane, 15(S)8-iso-prostaglandin F2 $\alpha$, in biological samples by GC-MS or GC-MS/MS coupled with immunoaffinity column chromatography, J. Chromatogr. B Anal. Technol. Biomed. Life Sci. 1019 (2016) 191-201.

[22] B. Donida, D.P. Marchetti, C.E.D. Jacques, G. Ribas, M. Deon, P. Manini, H.T. da Rosa, D.J. Moura, J. Saffi, R. Giugliani, C.R. Vargas, Oxidative profile exhibited by Mucopolysaccharidosis type IVA patients at diagnosis: increased keratan urinary levels, Mol. Genet. Metab. Rep. 11 (2017) 46-53.

[23] J. Klawitter, M. Haschke, T. Shokati, J. Klawitter, U. Christians, Quantification of 15-F2t-isoprostane in human plasma and urine: results from enzyme-linked immunoassay and liquid chromatography/tandem mass spectrometry cannot be compared, Rapid Commun. Mass Spectrom. 25 (2011) 463-468.

[24] L.A. García-Flores, S. Medina, R. Cejuela, J.M. Martínez-Sanz, C. Oger, J.M. Galano, T. Durand, T. Casas-Pina, P. Martínez-Hernández, F. Ferreres, A. Gil-Izquierdo, Assessment of oxidative stress biomarkers - neuroprostanes and dihomo-isoprostanes - in the urine of elite triathletes after two weeks of moderate-altitude training, Free Radic. Res. 50 (2016) 485-494.

[25] Y. Xiao, X. Fu, P. Pattengale, J. Dien Bard, Y.K. Xu, M.R. O'Gorman, A sensitive LCMS/MS method for the quantification of urinary 8-iso-prostaglandin F2 $\alpha$ (8-isoPGF2 $\alpha$ ) including pediatric reference interval, Clin. Chim. Acta 460 (2016) 128-134.

[26] I. Torres-Cuevas, A. Parra-Llorca, A. Sánchez-Illana, A. Nuñez-Ramiro,
J. Kuligowski, C. Cháfer-Pericás, M. Cernada, J. Escobar, M. Vento, Oxygen and oxidative stress in the perinatal period, Redox Biol. 12 (2017) 674-681.

[27] S. Medina, R. Domínguez-Perles, J.I. Gil, F. Ferreres, C. García-Viguera, J.M. Martínez-Sanz, A. Gil-Izquierdo, A ultra-pressure liquid chromatography/triple quadrupole tandem mass spectrometry method for the analysis of 13 eicosanoids in human urine and quantitative $24 \mathrm{~h}$ values in healthy volunteers in a controlled constant diet, Rapid Commun. Mass Spectrom. 26 (2012) 1249-1257.

[28] J. Fu, J.C. Schoeman, A.C. Harms, H.A. van Wietmarschen, R.J. Vreeken, R. Berger, B.V.J. Cuppen, F.P.J.G. Lafeber, J. van der Greef, T. Hankemeier, Metabolomics profiling of the free and total oxidised lipids in urine by LC-MS/MS: application in patients with rheumatoid arthritis, Anal. Bioanal. Chem. 408 (2016) 6307-6319.

[29] M.S. Albert, S.T. DeKosky, D. Dickson, B. Dubois, H.H. Feldman, N.C. Fox, A. Gamst D.M. Holtzman, W.J. Jagust, R.C. Petersen, P.J. Snyder, M.C. Carrillo, B. Thies, C.H. Phelps, The diagnosis of mild cognitive impairment due to Alzheimer's disease: recommendations from the National Institute on Aging-Alzheimer's Association workgroups on diagnostic guidelines for Alzheimer's disease, Alzheimers Dement. 7 (2011) 270-279.

[30] G.M. McKhann, D.S. Knopman, H. Chertkow, B.T. Hyman, C.R. Jack, C.H. Kawas, W.E. Klunk, W.J. Koroshetz, J.J. Manly, R. Mayeux, R.C. Mohs, J.C. Morris, M.N. Rossor, P. Scheltens, M.C. Carrillo, B. Thies, S. Weintraub, C.H. Phelps, The diagnosis of dementia due to Alzheimer's disease: recommendations from the National Institute on Aging-Alzheimer's Association workgroups on diagnostic guidelines for Alzheimer's disease, Alzheimers Dement. 7 (2011) 263-269.

[31] C. Randolph, Repeatable Battery for the Assessment of Neuropsychological Status MR, The Psychological Coporation, San Antonio, TX, 1998.

[32] R.I. Pfeffer, T.T. Kurosaki, C.H. Harrah, J.M. Chance, S. Filos, Measurement of functional activities in older adults in the community, J. Gerontol. 37 (1982) 323-329.

[33] C.P. Hughes, L. Berg, W.L. Danziger, L.A. Coben, R.L. Martin, A new clinical scale for the staging of dementia, Br. J. Psychiatry 140 (1982) 566-572.

[34] A. de la Torre, Y.Y. Lee, A. Mazzoni, A. Guy, V. Bultel-Poncé, T. Durand, C. Oger, J.C. Lee, J.M. Galano, Total syntheses and in vivo quantitation of novel neurofuran and dihomo-isofuran derived from docosahexaenoic acid and adrenic acid, Chemistry 21 (2015) 2442-2446.

[35] C. Cháfer-Pericás, L. Rahkonen, A. Sánchez-Illana, J. Kuligowski, I. Torres-Cuevas, M. Cernada, E. Cubells, A. Nuñez-Ramiro, S. Andersson, M. Vento, J. Escobar, Ultra high performance liquid chromatography coupled to tandem mass spectrometry determination of lipid peroxidation biomarkers in newborn serum samples, Anal. Chim. Acta 886 (2015) 214-220.

[36] J. Kuligowski, J. Escobar, G. Quintás, I. Lliso, I. Torres-Cuevas, A. Nuñez, E. Cubells, D. Rook, J.B. van Goudoever, M. Vento, Analysis of lipid peroxidation biomarkers in extremely low gestational age neonate urines by UPLC-MS/MS, Anal. Bioanal. Chem. (2014), http://dx.doi.org/10.1007/s00216-014-7824-6.

[37] Guideline on bioanalytical method validation, European Medicines Agency, 2011.

[38] L.A. García-Flores, S. Medina, P. Martínez-Hernández, C. Oger, J.M. Galano, T. Durand, T. Casas-Pina, F. Ferreres, A. Gil-Izquierdo, Snapshot situation of oxidative degradation of the nervous system, kidney, and adrenal glands biomarkers neuroprostane and dihomo-isoprostanes-urinary biomarkers from infancy to elderly adults, Redox Biol. 11 (2017) 586-591.

[39] E. Ricciotti, G.A. FitzGerald, Prostaglandins and Inflammation, Arterioscler. Thromb. Vasc. Biol. 31 (2011) 986-1000.

[40] N. Bernoud-Hubac, S.S. Davies, O. Boutaud, T.J. Montine, L.J. Roberts, Formation of highly reactive $\gamma$-ketoaldehydes (neuroketals) as products of the neuroprostane pathway, J. Biol. Chem. 276 (2001) 30964-30970.

[41] A. Lloret, T. Fuchsberger, E. Giraldo, J. Vina, Reductive stress: a new concept in Alzheimer's Disease, Curr. Alzheimer Res. 13 (2016) 206-211.

[42] I. de las Heras-Gómez, S. Medina, P. Casas-Pina, L. Marín-Soler, A. Tomás, P. Martínez-Hernández, C. Oger, J.M. Galano, T. Durand, L. Jimeno, S. Llorente, E. Lozoya, F. Ferreres, A. Gil-Izquierdo, Potential applications of lipid peroxidation products - F4-neuroprostanes, F3-neuroprostanesn-6 DPA,F 2-dihomo-isoprostanes and F2-isoprostanes - in the evaluation of the allograft function in renal transplantation, Free Radic. Biol. Med. 104 (2017) 178-184. 